\title{
Journal of Cardiovascular Magnetic

Poster presentation

\section{The effect of regurgitant volume on left ventricular volumes and dimensions in patients with isolated aortic or mitral regurgitation

\author{
Seth Uretsky*1, Surinder S Khokhar ${ }^{1}$, Azhar Supariwala ${ }^{1}$, \\ Pushpalatha Nidadovolu ${ }^{1}$, Cindy Comeau ${ }^{2}$, Oleg Subayev ${ }^{2}$, \\ Francesca Campanile ${ }^{2}$ and Steven D Wolff ${ }^{2}$
}

Address: ${ }^{1}$ St. Luke's and Roosevelt Hospitals, New York, NY, USA and ${ }^{2}$ Advanced Cardiovascular Imaging, New York, NY, USA

* Corresponding author

from 13th Annual SCMR Scientific Sessions

Phoenix, AZ, USA. 21-24 January 2010

Published: 21 January 2010

Journal of Cardiovascular Magnetic Resonance 20 I0, I2(Suppl I):P282 doi:10.I I86/I532-429X-12-SI-P282

This abstract is available from: http://jcmr-online.com/content/I2/SI/P282

(c) 2010 Uretsky et al; licensee BioMed Central Ltd.

\section{Introduction}

The treatment of patients with aortic regurgitation (AR) or mitral regurgitation (MR) relies on the accurate assessment of the severity of the regurgitation and its effect on left ventricular (LV) size and function. CMR is an excellent tool for quantifying regurgitant volumes and LV size and function. The 2006 AHA/ACC management guidelines for the therapy of patients with AR or MR describe LV size in terms of linear dimensions (i.e. end-diastolic and endsystolic dimension). LV volumes that correspond to these linear dimensions have not been published in the peerreviewed literature.

\section{Purpose}

To determine the effect of regurgitant volume on LV volumes and chamber dimensions in patients with isolated $\mathrm{AR}$ or MR and preserved LV function.

\section{Methods}

This study comprises 62 consecutive CMR exams in 57 patients with isolated AR or MR. LV volumes were determined from short and long-axis 1.5 T FIESTA images using a semiautomated algorithm (ReportCard 4.0). Flow in the proximal aorta and pulmonary artery was assessed with phase-contrast imaging. Baseline correction was performed using a stationary phantom. AR volume was determined by integrating aortic blood flow throughout diastole. MR volume was determined as the difference between LV stroke volume and pulmonary artery flow. To determine the reproducibility of AR and MR regurgitant volume, a second blinded analysis was made according to the same method.

\section{Results}

There is a strong, linear relationship between regurgitant volume and $\mathrm{LV}$ end-diastolic volume index $\left(\mathrm{AR} \mathrm{r}^{2}=0.8\right.$, $M R r^{2}=0.8$ ) (figure). Bland Altman analysis of regurgitant volume shows little interobserver variation (AR: $0.6+4$ $\mathrm{ml}$; MR: $4+6 \mathrm{ml}$ ). The correlation is much poorer between regurgitant volume and commonly used clinical linear measures such as end-systolic dimension $\left(\mathrm{MR}^{2}=\right.$ $\left.0.2, \mathrm{AR}^{2}=0.5\right)$. Linear regression is used to determine the $\mathrm{LV}$ volumes that correspond to the linear dimensions currently recommended in the 2006 AHA/ACC management guidelines (Figure 1, Table 1).

\section{Conclusion}

MRI is a robust technique for quantification of regurgitant volume in patients with AR or MR and preserved LV function. Ventricular volumes show a stronger correlation with regurgitant volume than linear dimensions, suggesting LV volumes better reflect ventricular remodeling in patients with isolated mitral or aortic regurgitation. For a given regurgitant volume, AR results in greater LV enlargement than patients with MR, likely due to the fact that MR is a pure volume lesion whereas AR is both a pressure and a volume lesion. Ventricular volumes that correspond to published recommended linear dimensions are determined to guide the timing of surgical intervention. 


\begin{tabular}{|c|c|c|}
\hline \multicolumn{1}{|l|}{ Table } & LV Volume Index $\left(\mathrm{ml}^{\mathbf{2}} \mathbf{m}^{2}\right)$ & LV Volume $(\mathrm{ml})$ \\
\hline Mitral Regurgitation & & \\
\hline ESD $=\mathbf{4 0 m m}$ & ESVI: 29 & ESV: 58 \\
\hline Aortic Regurgitation & & \\
\hline ESD $=55 \mathrm{~mm}$ & ESVI: 51 & ESV: 100 \\
\hline EDD $=\mathbf{7 5 m m}$ & EDVI: 129 & EDV: 260 \\
\hline
\end{tabular}

\section{Figure I}

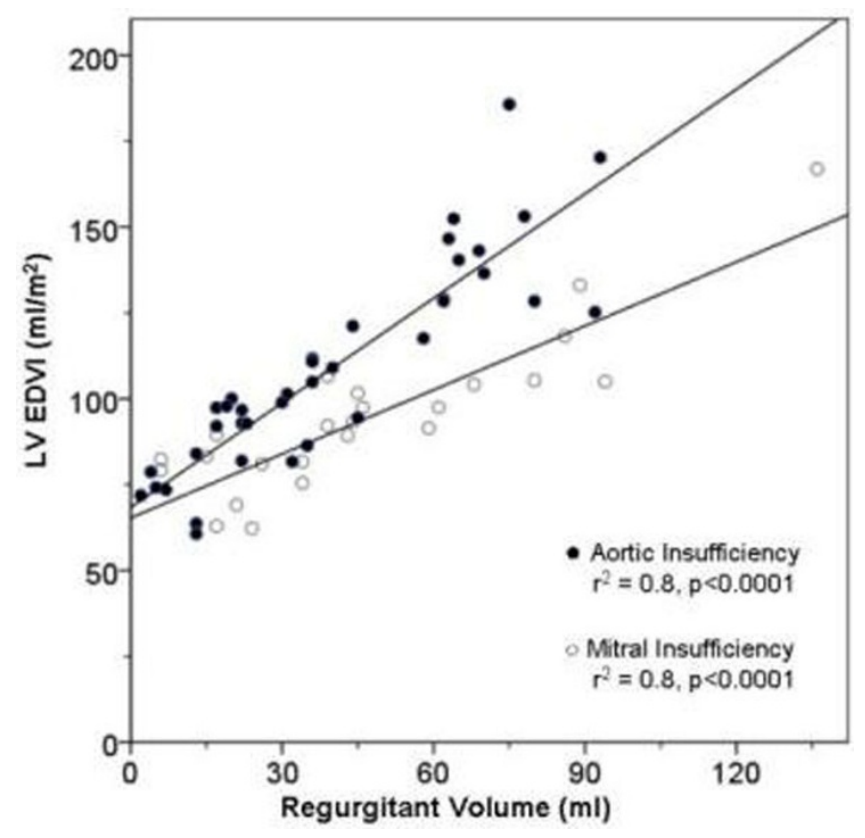

Figure 2
Publish with Bio Med Central and every scientist can read your work free of charge

"BioMed Central will be the most significant development for disseminating the results of biomedical research in our lifetime. "

Sir Paul Nurse, Cancer Research UK

Your research papers will be:

- available free of charge to the entire biomedical community

- peer reviewed and published immediately upon acceptance

- cited in PubMed and archived on PubMed Central

- yours - you keep the copyright

Submit your manuscript here:

http://www.biomedcentral.com/info/publishing_adv.asp 